\title{
Using Sleep Mode Mechanism to Improve Energy Efficiency in Heterogenous Network
}

\author{
Ali Merwan Shakor, Omar Jasim, David Cheng \\ California State University, Fullerton \\ 800 N. State College Blvd, Fullerton, California 92834
}

\begin{abstract}
The number of users for developed devices (e.g., mobile, tablet, laptop, iPad, computer) increased rapidly. This trend is expected to continue in the next upcoming years. Thus, the number of users will rapidly increase, which will cause a high demand for capacity in wireless access networks. In addition, they will cause high energy and power consumption. Heterogeneous network (HetNet) is one of the most promising network approaches to achieve high capacity and improve energy efficiency (EE). In This piper, will investigate the sleep mode mechanism to improve $\mathrm{EE}$ and reduce power consumption. When companies design communication network systems, they are considered the network service at peak load hour. Peak traffic load happens a few hours a day, but the rest of the time most of the power is wasted. The sleep mode mechanism is used by switching Micro and Pico base stations (BSs) when the traffic load is low or medium. Simulation results show that EE gain can be achieved $46.68 \%$ and $79.77 \%$, when the traffic load is medium or low.
\end{abstract}

\section{General Terms}

Energy Efficiency improving and Power Consumption reducing

\section{Keywords}

Heterogeneous network, energy efficiency, power consumption, sleep mode.

\section{INTRODUCTION}

The massive growth in the number of users for development devices has caused data traffic in the mobile network. It is clear that the service offers available to customers today is not similar to the offers from a few years ago. For instance, there are many applications such as (Facebook, Tango, Viper, and so on) which customers find indispensable. In the past, people only used cellphones for calling and sending messages, but now most people use cellphones for a variety of purposes. For example, a cellphone can be used for making calls, sending messages, video calling, sending pictures, chatting, and so on. Although, these applications can be so beneficial, they have caused a dramatic increase in data traffic. In comparison between now and the past, depending on the data traffic, it is so clear that the data traffic in the network has sharply increased. The increase in both penetration rate of mobile device usage and data usage per user caused a dramatic increase in mobile users and network traffic which led to an increase in energy consumption in wireless networks [1,2] This dramatic growth in energy consumption led to increase global carbon emission and effect on climate [3]. A study by Information and Communications Technology (ICT) estimated that over $4 \%$ of global carbon dioxide emissions by communication network (around 1 billion tons, approximately equal to that of aviation industry and one fourth of emission by cars worldwide) and for about $10 \%$ of global electricity consumption as of early 2013 [3]. They expected global carbon emissions grow every year, and they thought carbon emissions will exceed $8 \%$ by the year 2020 [4]. There are some researches accounted the emissions from one towers Base Station (BS) has almost 78 million tons. this amount from carbon dioxide emissions considered is a huge, if we compared with emissions from cars and airplanes. It is equal to emissions from 15 million cars, or 300000 trip flights between Paris and New York [4]. Depending to theses researches the amount of carbon dioxide emissions is not small number, we cannot ignore the negative affect for carbon dioxide. The continuation in increase energy consumption made many researchers to think how reduced the energy consumption. The carbon dioxide emissions already reduce when the energy consumption reduce. There are many methods how to reduce the energy consumption and improve EE. Sleep mode technique one of this method in this paper we will investigate that to improve $\mathrm{EE}$.

\section{POWER CONSUMPTION IN CELLULAR NETWORK}

The massive growth cellular BS from a small number to millions led some researchers to analysis power consumption in cellular network. Each base station consumes about 25 MWh per year [5]. This rabid growth in number of BS led to increase energy cost to operate them and amount of carbon dioxide emission also increase [6]. Also, BS consumes around $60 \%$ from power cellular network this led us to use sleep mode technique to reduce the power consumption in BS, Mobile Switching consumes 20\%, Data Center and Retail consumes about $20 \%$, but Retail consumes less than Data Center. Fig 1 explains power consumption in cellular network. Sectors BS that have HSPA (high speed packet access) consumed about 800 to $1500 \mathrm{~W}$ per BS $[5,7]$.

\section{Power consumption in cellular networks}

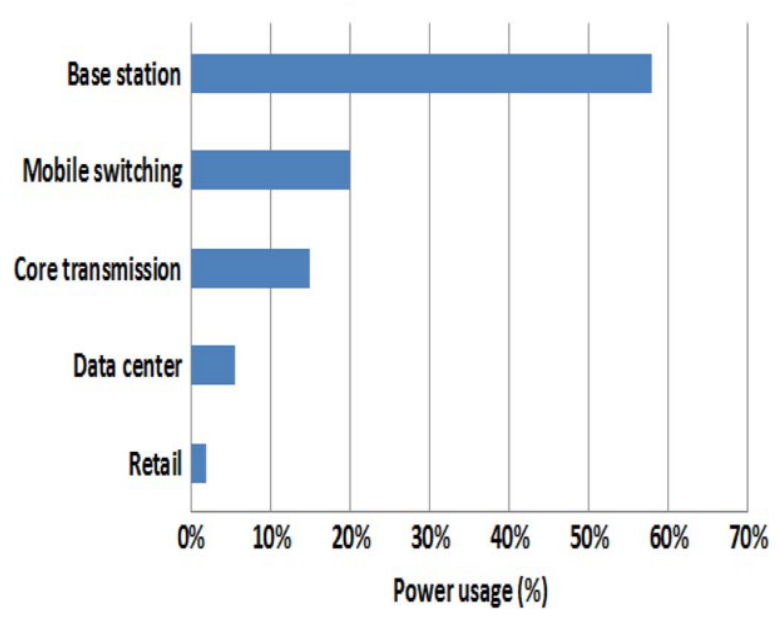

Fig 1: Power consumption in cellular network [6] 


\section{HETEROGENOUS NETWORK}

3.1 Heterogeneous Network (HetNet) is considered one of the most crucial methods for achieving higher capacity, data rate, and large coverage area [8]. It is a very convenient way to address the data traffic problem in cellular networks. Quality of service requirements are considered more stringent in HetNet, that makes the user more comfortable. In HetNet, the users are always very close to a BS, which cause higher signal-to-interference-plus-noise ratios (SINR), thereby in turn offer enhanced robustness and quality of service to the user. HetNet consists of a combination of macrocells (high power node) and low-power modes, such as microcells, picocells, femtocells, and relays [9]. Fig 2 shows this combination. For this reason, path loss in HetNet is less than other networks. In HetNet, the distance between the user and nod or network is smaller in comparison to other networks. In addition, HetNet is considered a sound method to improve EE and reduce energy consumption [8]. There have many techniques in HetNet to enhance EE, we will focus in this paper to sleep mode mechanism.

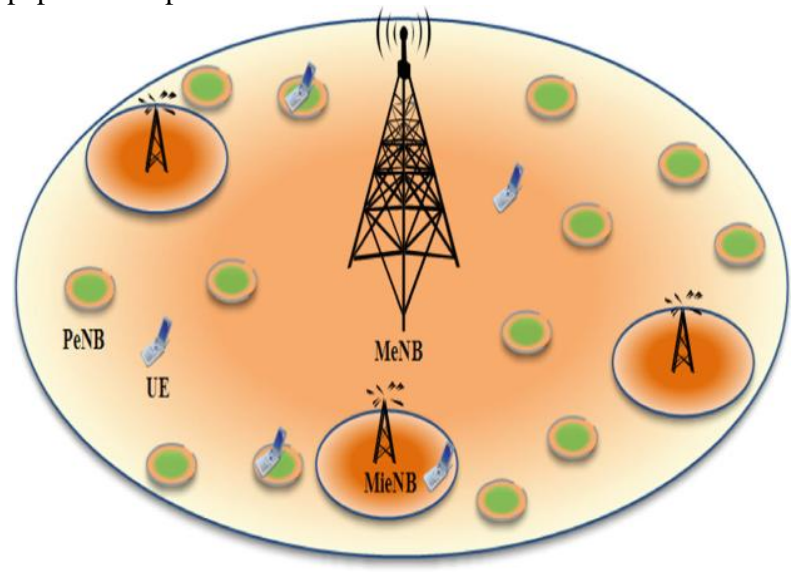

Fig 1: Heterogeneous Network model [8]

\section{SLEEP MODE TECHNIQUE}

A high traffic load leads to a cellular network design that can support a high traffic load, however, during a light traffic load the energy consumed by the cellular network is generally wasted [10]. According to [8], the sleep mode technique is used to save energy when the traffic load is light by switching off one type of $\mathrm{BS}$ which is explained in following equation.

$\mathrm{PcHet}=\mathrm{Q} * \mathrm{PcMeNB}+\mathrm{M} * \mathrm{PcMieNB}+(\mathrm{P}-\mathrm{H}) * \mathrm{PcPeNB}(1)$ $\mathrm{PcHet}=$ power consumption in HetNet.

$\mathrm{PcMeNB}=$ power consumption in macro BS.

$\mathrm{PcMieNB}=$ power consumption in micro BS.

$\mathrm{PcPeNB}=$ power consumption in pico BS.

$\mathrm{Q}, \mathrm{M}, \mathrm{P}=$ number of macro, micro and pico BS respectively.

$\mathrm{H}=$ number of pico BS in sleep mode.

By using this technique, they achieved improvement in EE 69, 33 , and $7 \%$, when traffic load is 20,50 , and $90 \%$, respectively. This paper will use different scenarios when switching off BSs and switching off two types of BSs (micro and pico), when the traffic load is light. When switching off two types BSs equation (1) becomes
$\mathrm{PcHet}=\mathrm{Q} * \mathrm{PcMeNB}+(\mathrm{M}-\mathrm{K}) * \mathrm{PcMieNB}+(\mathrm{P}-$ H) $* \mathrm{PcPeNB}$

$\mathrm{K}$ : number of micro BS in sleep mode.

Area power consumption (APC) of the HetNet relative to its size is equal to power consumption divided by area in HetNet [11].

$\mathrm{APC}=\mathrm{PcHet} /$ Ahet

With sleep mode equation (2) become as

$\mathrm{APC}=(\mathrm{Q} * \mathrm{PcMeNB}+(\mathrm{M}-\mathrm{K}) * \mathrm{PcMieNB}+(\mathrm{P}-$

$\mathrm{H}) * \mathrm{PcPeNB}) /$ Ahet

In urban areas, the daily traffic load profile indicates that the BS capacity is fully used only for a few hours, which is presented in [12]. Fewer users are served during the remaining time. Significant energy saving potential occurs in cellular networks when traffic load variation is offered. The fraction of maximum capacity of a BS is defined as the load of a BS [8]. When all resources are available for one or more users, the portion of RB allocated for users is described as the load factor (L), which defines the traffic load in $[13,14]$.

$\mathrm{L}=\mathrm{Nu} / \mathrm{NT}$

$\mathrm{Nu}$ : RBs utilized by the BS users.

NT: Total RBs available to this BS

Energy efficiency in HetNet is equal to the ratio of the achievable data rate divided by the total power consumption in network $[8,15]$.

EEhet $=$

$$
\frac{\sum_{q=1}^{Q} R M e N B, q+\sum_{m}^{M} \text { RMieNB, } m+\sum_{p=1}^{P} R P e N B, p}{\sum_{q=1}^{Q} \text { PcMeNB, } q+\sum_{m}^{M} \text { PcMieNB }, m+\sum_{p=1}^{P} \text { PcPNB, } p}
$$

where PcMeNB,q, PcMieNB,m and PcPeNB,p denote to the power consumption in Macro, Micro and Pico BS respectively, RMeNB, q, RMieNB, $m$ and RPeNB, p denote the achievable average date rate provided by same BS respectively. The rate for the $n$-th user can be calculated according to the modified Shannon's formula [16-18].

$r_{n}=\eta_{B W} \eta B W_{n} \log _{2}\left(1+\frac{S N R_{n}}{\eta S N R}\right)$

П_BW: accounts for the system bandwidth efficiency of LTE. ฤSNR: SNR implementation efficiency of LTE.

$\eta$ : correction factor that should nominally be equal to one [16].

BW: band width can be expressed as the number of resource block (RB).

When sleep mode technique is used we can rewrite equation (7) as following.

EEhet $=$

$\frac{Q * R M e N B+(M-K) * R M i e N B+(P-H) * R P}{Q * P c M e N B+(M-K) * P c M i e N B+(P-H) * P C}$

Energy efficiency gain is solved by using the following formula

Energy efficiency gain $=$

$E E_{\text {with sleep mode }}-E E_{\text {without sleep mode }}$ *100\% 


\section{SIMULATION}

The simulation is done by using MATLAB, which includes all of the equations explained in this Chapter. Also, there are other parameters used in this program which can be found in Table 1.

Table 1. Simulation Parameters [8]

\begin{tabular}{|c|c|}
\hline Parameter & Value \\
\hline Carrier frequency & $2.6 \mathrm{GHz}$ \\
\hline Bandwidth & $10 \mathrm{MHZ}$ \\
\hline $\begin{array}{l}\text { Ptx for MeNB, MieNB and } \\
\text { PeNB }\end{array}$ & $46,35,30 \mathrm{dBm}[19]$ \\
\hline Channel model & 3GPP typical urban [20] \\
\hline Penetration loss & $20 \mathrm{~dB}$ \\
\hline $\begin{array}{l}\text { Modulation and coding } \\
\text { scheme }\end{array}$ & $\begin{array}{l}15 \text { different sets defined in } \\
{[18]}\end{array}$ \\
\hline $\begin{array}{l}\text { No. of sectors for MeNB, } \\
\text { MieNB and PeNB }\end{array}$ & $3,1,1$ \\
\hline Thermal noise & $-174 \mathrm{dBm} / \mathrm{Hz}$ \\
\hline Noise Figure & 9dB (downlink) \\
\hline Coverage degree & $95 \%$ \\
\hline $\begin{array}{l}\text { Power consumption } \\
\text { parameters }\end{array}$ & $\begin{array}{l}\text { MeNB: } \mathrm{Ai}=21.45 ; \mathrm{Bi}=354.44 \\
{[21]} \\
\text { MieNB: } \mathrm{Ai}=7.84 ; \mathrm{Bi}=71.5 \\
{[21]} \\
\text { PeNB: } \mathrm{Ai}=5.5 ; \mathrm{Bi}=38[21]\end{array}$ \\
\hline
\end{tabular}

\section{RESULTS AND DISCUSSION}

This section presents EE enhancement by using sleep mode technique and scenarios. Sleep mode mechanism can be applied to various traffic load destruction in network. In sleep mode, there are many scenarios which can be applied to improve EE in HetNet. The following Figures present a performance simulation to improve EE, these Figures explain that sleep mode mechanism is very beneficial to improve EE when there is light traffic load.

The first scenario involves turning off one type of BS when the traffic load is not full $(100 \%)$. This scenario includes switching off some Pico BSs to reduce power consumption consumed by these stations. For instance, if there are 10 Pico BSs when one of them is switched off, there will be a transfer of load from that BS to others BSs in the network. Figure 3 presents a performance simulation of sleep mode mechanism to improve EE when traffic load is 20,50 , and 90 percent, respectively. The $\mathrm{x}$-axis represents $\mathrm{EE}$ with and without sleep mode and the $y$-axis represents the traffic load. Figure 3 shows how much EE improves when the sleep mode technique is applied. Figure 4 presents a performance simulation with EE gain. This Figure shows EE gain by applying the sleep mode mechanism when the traffic load is 20,50 , and $90 \%$, which have an EE gain equal to 70.9, 38.9 and $6.9 \%$, respectively.

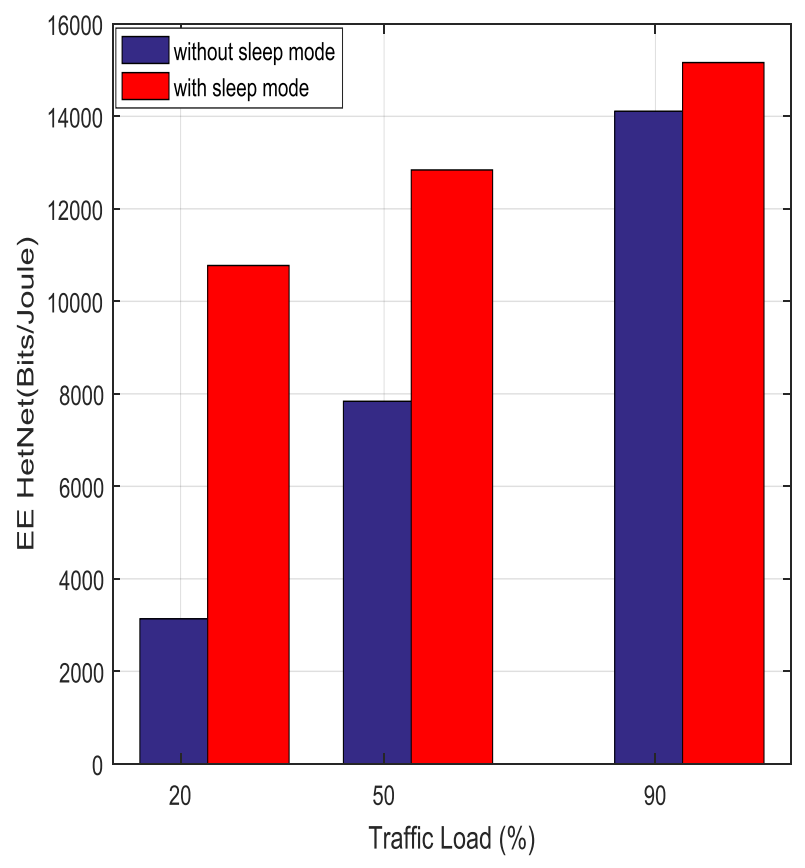

Fig 3: EE in HetNet with and without sleep mode in first scenario

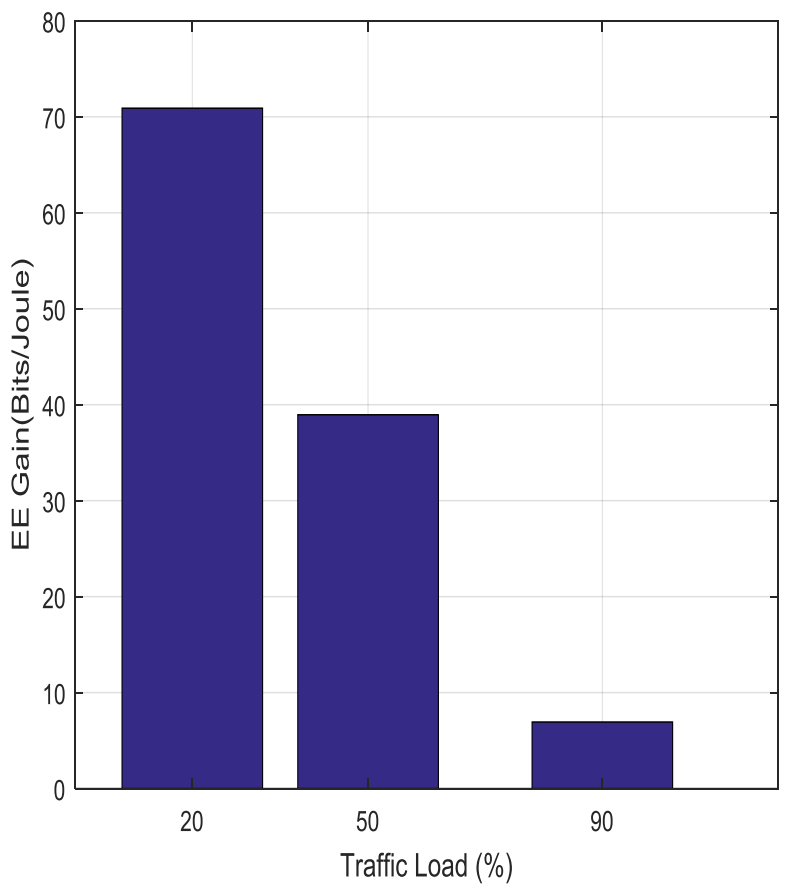

Fig 4: EE Gain in First Scenario

The second scenario to improve EE in sleep mode technique involves switching off two types of BSs (Pico and Micro). When the traffic load is not heavily used, this scenario can reduce energy consumption by Pico and Micro BSs. In this scenario, switching off Pico and Micro BSs means the load in Pico BS will transfer to another Pico BS in the same network and the load in Micro BS will transfer to another Micro BS. Figure 5 shows EE improvement with and without sleep mode technique in this scenario. Figure 6 shows EE gain in this 
scenario. EE gain is equal to $79.77,46.68$, and $6.93 \%$ when traffic load is 20,50 and $90 \%$, respectively.

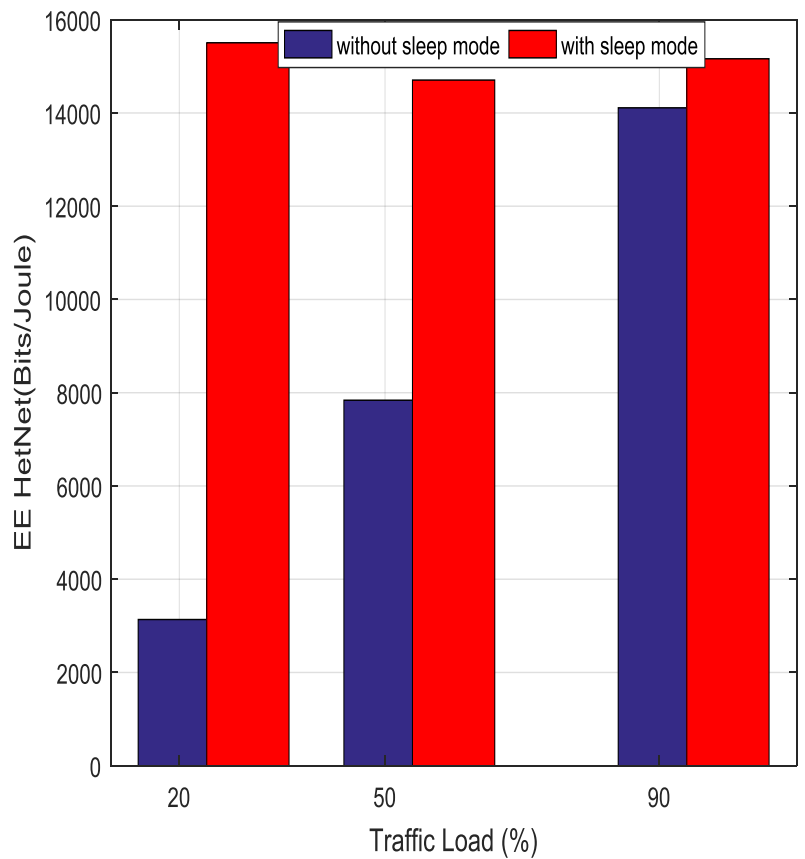

Fig 5: EE in HetNet with and without sleep mode in second scenario

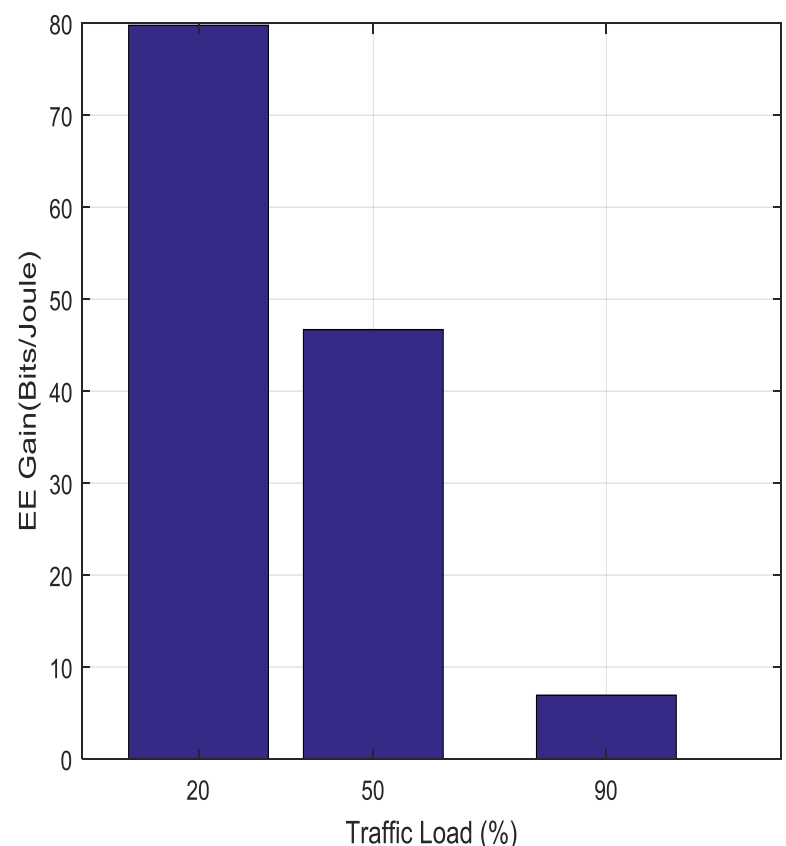

Fig 6: EE Gain in Second Scenario

Power consumption in HetNet (Macro, Micro, and Pico) BSs is reduced by using the sleep mode mechanism. The amount of power reduced in HetNet is dependent on the number of BSs (Micro and Pico) switched off during sleep mode. Figure 7,8 , and 9 explain how much power consumption reduced. The $y$-axis represents the area power consumption (APC) and $\mathrm{x}$-axis represents the Macro Radius. We understand from these Figures the large power consumption reduction happens when load traffic is low. From these and previous Figures shown, the sleep mode technique is a very effective method to reduce power consumption and increase EE in HetNet when load traffic is light.

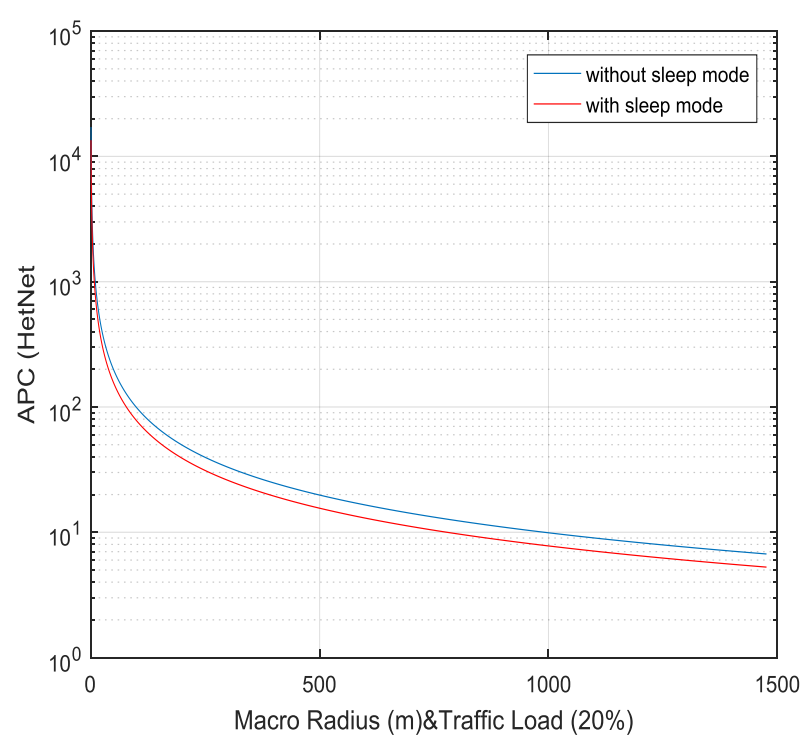

Fig 7: APC when traffic load 20\%

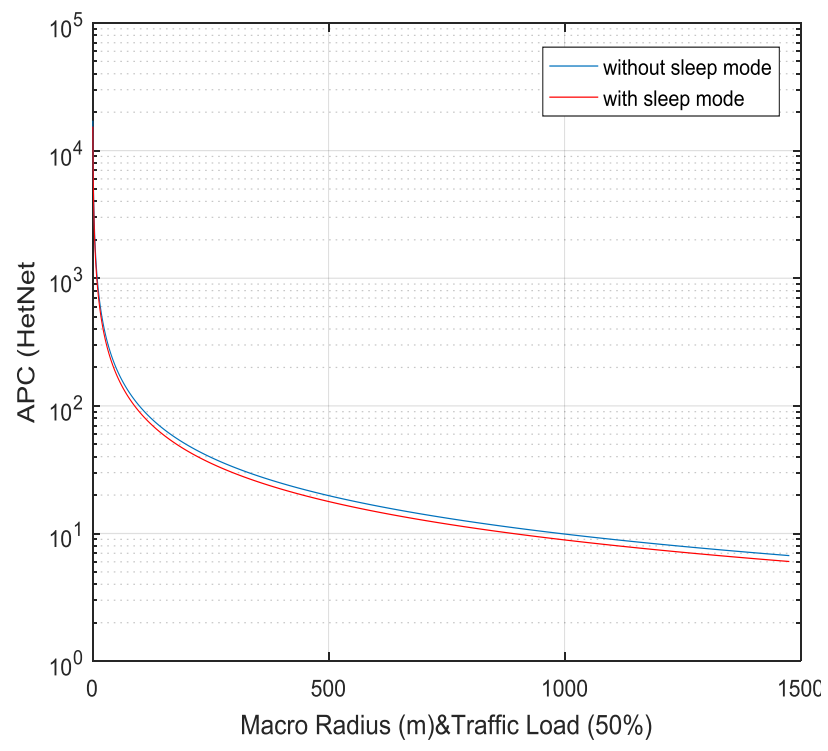

Fig 8: APC when traffic load 50\%

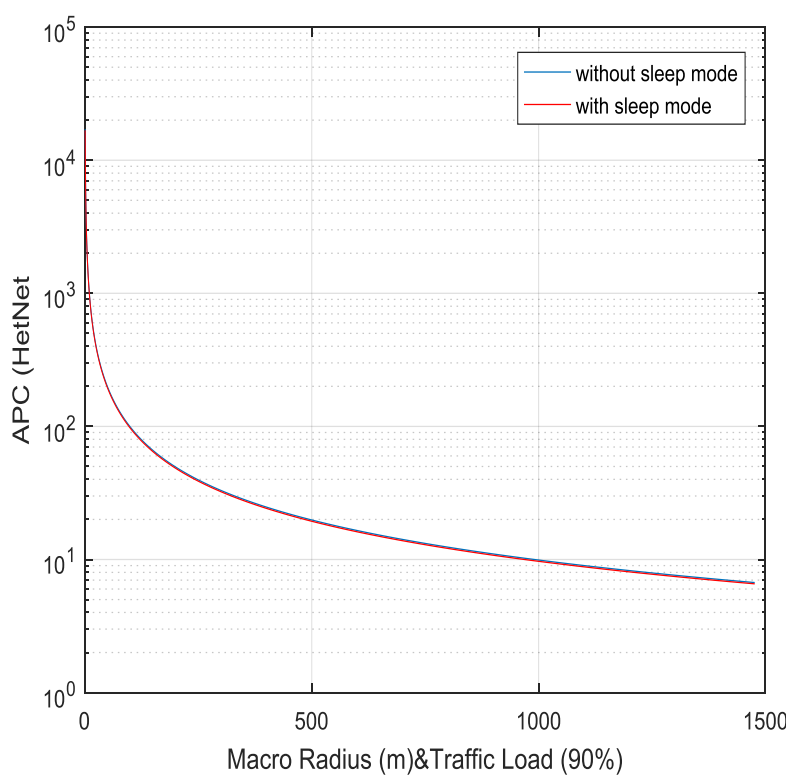

Fig 9: APC when traffic load 90\% 


\section{CONCLUSION AND FUTURE WORK}

The HetNet is one of the most promising network approaches to achieve high capacity and network EE. The results of this study show that sleep mode mechanism is a very effective method to improve EE and reduce power consumption in the HetNet. The sleep mode mechanism is used by switching Micro and Pico BSs depending on the traffic load. Simulation results show that EE gain can be 6.93, 46.68, and $79.77 \%$, when the traffic load is 90,50 , or $20 \%$, respectively. In this scenario, the traffic load in awake BSs is full load, which is $100 \%$. The maximum EE gain is achieved when the traffic load is $20 \%$, which is low.

Future work should be applied in a real network to reduce power consumption in a practical network. Furthermore, future research should be expanded to study various regions, such as urban, suburban, and rural areas, which affect EE. Also, transmitter power affect in HetNet (Macro, Micro, and Pico) should be investigated. In addition, future research should investigate uplink and downlink interference effects to improve EE.

\section{REFERENCES}

[1] "Cisco Visual Networking Index: Global Mobile Data Traffic Forecast Update, 2016-2021 White Paper," 2017. [Online]. Available: http://www.cisco.com/c/en/us/solutions/collateral/service -provider/visual-networking-index-vni/mobile-whitepaper-c11-520862.html. [Accessed 202 2017].

[2] T. S. Ng, T. C. Chuah and Y. F. Tan, "QoS-based radio network dimensioning for LTE networks with heavy real-time traffic," International Journal of Communication Systems,DOI: 10.1002/dac.2447, 2012

[3] Eur. Commission Release, "Digital agenda: Global tech sector measures its carbon footprint," Brussels, Belgium, Mar. 2013. [Online]. Available: http://europa.eu/rapid/press-release_IP-13-231_en.htm

[4] T. Langedem, "Reducing the carbon footprint of ICT devices, platforms and networks," Green Touch, Amsterdam, The Netherlands, Nov. 2012. [Online].

[5] X. Chu, D. Lopez-Perez, Y. Yang and F. Gunnarsson, Heterogeneous Cellular Networks:Theory, Simulation and Deployment, Cambridge: Cambridge University Press, 2013.

[6] C. Han et al., "Green radio: Radio techniques to enable energy-efficientwireless networks," IEEE Commun. Mag., vol. 49, no. 6, pp. 46-54, Jun. 2011.

[7] G. Auer, V. Giannini, I. Godor, P. Skillermark, M. Olsson, M. A. Imran, D. Sabella, M. J. Gonzalez, C. Desset and O. Blume, "Cellular Energy Efficiency Evaluation Framework," Vehicular Technology Conference (VTC Spring), IEEE 73rd, DOI: 10.1109/VETECS.2011.5956750, 2011.

[8] A. A. Abdulkafi, T. S. Kiong, D. Chieng, A. Ting and J. Koh, "Energy Efficiency Improvements in Heterogeneous Network Through Traffic Load Balancing and Sleep Mode Mechanisms," Wireless Personal Communications doi:10.1007/s11277-013-1460-x, Springer Science Business Media New York 2013, vol. 75, p. 2151-2164, 2014.

[9] "3rd Generation Partnership Project; Technical Specification Group Radio Access Network; Evolved
Universal Terrestrial Radio Access (E-UTRA); Further advancements for E-UTRA physical layer aspects (Release 9),3GPP TR 36.814 V9.0.0," 2010. [Online]. Available: $\quad$ http://www.qtc.jp/3GPP/Specs/36814900.pdf.

[10] S. Tombaz, M. Usman and J. Zander, "Energy efficiency improvements through heterogeneous networks in diverse traffic distribution scenarios," Communications and Networking in China (CHINACOM), 2011 6th International ICST Conference on, DOI: 10.1109/ChinaCom.2011.6158246, 2011.

[11] F. Richter, A. J. Fehske and G. P. Fettweis, "Energy Efficiency Aspects of Base Station Deployment Strategies for Cellular Networks," Vehicular Technology Conference Fall (VTC 2009-Fall), IEEE, DOI: 10.1109/VETECF.2009.5379031, Sept. 2009.

[12] EARTH project deliverable, D2.3. (2010). Energy efficiency analysis of the reference systems, areas of improvements and target breakdown.

[13] M. W. Arshad, A. Vastberg and T. Edler, "Energy efficiency improvement through pico base stations for a green field operator," IEEE, June 2012.

[14] M. W. Arshad, A. Vastberg and T. Edler, "Energy efficiency gains through traffic offloading and traffic expansion in joint macro pico deployment," Wireless Communications and Networking Conference (WCNC), IEEE, DOI: 10.1109/WCNC.2012.6214158, June 2012.

[15] W. Wang and G. Shen, "Energy Efficiency of Heterogeneous Cellular Network," Vehicular Technology Conference Fall (VTC 2010-Fall), IEEE 72nd, DOI: 10.1109/VETECF.2010.5594361, October 2010 .

[16] H. Holma and A. Toskala, " LTE for UMTS-OFDMA and SC-FDMA based radio access.," Chichester: Wiley., 2009.

[17] P. Mogensen, W. Na, I. Z. Kovacs, F. Frederiksen, et all, "LTE Capacity Compared to the Shannon Bound," Vehicular Technology Conference, 2007. VTC2007Spring. IEEE 65th, DOI: 10.1109/VETECS.2007.260, May 2007.

[18] S. Sesia, I. Toufik and M. Baker, "LTE-The UMTS long term evolution: From theory to practice (2nd ed.).," New York: Wiley., 2011.

[19] W. Wang and G. Shen, "Energy Efficiency of Heterogeneous Cellular Network," Vehicular Technology Conference Fall (VTC 2010-Fall), IEEE 72nd, DOI: 10.1109/VETECF.2010.5594361, October 2010 .

[20] 3GPP TR 36.814 V9.0.0. (2010). Technical Specification Group Radio Access Network, Evolved Universal Terrestrial Radio Access (E-UTRA), further advancements for E-UTRA physical layer aspects, (Release 9).

[21] S. Tombaz, M. Usman and J. Zander, "Usman, M., \& Zander, J. Energy efficiency improvements through heterogeneous networks in diverse traffic distribution scenarios," In Proceedings of international conference on communications and networking in China (CHINACOM) (pp. 1-6)., 2011. 